Check for updates

Cite this: RSC Adv., 2019, 9, 38486

Received 25th September 2019 Accepted 20th November 2019

DOI: 10.1039/c9ra07798g

rsc.li/rsc-advances

\section{Separation performance of $p$-tert- butyl(tetradecyloxy)calix[6]arene as a stationary phase for capillary gas chromatography $\dagger$}

\author{
Tao Sun, (D) ${ }^{* a}$ Xiaomin Shuai, ${ }^{b}$ Yujie Chen, ${ }^{a}$ Xinyu Zhao, ${ }^{a}$ Qianqian Song, ${ }^{a}$ Kaixin Ren, ${ }^{a}$ \\ Xingxing Jiang, ${ }^{a}$ Shaoqiang $\mathrm{Hu}\left(\mathrm{ID}^{\mathrm{a}}\right.$ and Zhiqiang $\mathrm{Cai}^{\star b}$
}

\begin{abstract}
This work presents the first example of the utilization of $p$-tert-butyl(tetradecyloxy)calix[6]arene (C6A-C10) as a stationary phase for capillary gas chromatographic (GC) separation. The statically coated C6A-C10 column showed a column efficiency of 3293 plates per $\mathrm{m}$ and had a nonpolar nature. Its selectivity and retention behaviour were investigated using a number of mixtures of diverse analytes and their isomers. As a result, the C6A-C10 column exhibited high resolving capability for aliphatic and aromatic analytes from apolar to polar nature, especially for positional, structural and cis-/trans-isomers. Moreover, the C6A-C10 column showed thermal stability up to $240{ }^{\circ} \mathrm{C}$. In addition, it was applied for the determination of isomer impurities in real samples, proving its good potential for practical GC analysis.
\end{abstract}

\section{Introduction}

Calixarene, is a typical representative of third-generation host molecules after crown ether and cyclodextrin. ${ }^{1}$ The calixarene skeleton possesses a bow-shaped cavity with polar (lower-rim) and nonpolar (upper-rim) properties. ${ }^{2}$ Usually, the upper rim is generally decorated by the presence of tert-butyl groups, whereas the lower rim presents phenolic $\mathrm{OH}$ groups that can also be widely functionalised. Calixarenes with the characteristic 3D cavity provide a useful platform for designing new functionalized host molecules, and provide various binding sites for anion, cation, and organic molecule recognition. ${ }^{3-6}$ Thus, the obtained calixarenes show potential applications in catalysis, molecular recognition, chemical sensing, and separation science. ${ }^{7-14}$ Calixarenes containing four, six, and eight aryl units (the "major" calixarenes) can be easily prepared in good to excellent yields with high states of purity. The calix $[4,6,8]$ arenes have inner cavity diameters of $3.0 \AA$, $7.6 \AA$, and $11.7 \AA$, respectively. ${ }^{15}$

The inner cavity size of calix[6]arene is moderate, which can provide unique shape selectivity and host-guest recognition interactions with guest molecules. ${ }^{16-18}$ Additionally, calix[6] arene is characterised by high thermal and thermal stability. ${ }^{19}$

${ }^{a}$ College of Chemistry and Chemical Engineering, Henan Key Laboratory of Function-Oriented Porous Materials, Luoyang Normal University, Luoyang 471934, P. R. China.E-mail:suntao2226@163.com; suntao@lynu.edu.cn

${ }^{b}$ Liaoning Province Engineering Research Center for Fine Chemical Engineering of Aromatics Downstream, School of Petrochemical Engineering, Shenyang University of Technology, Liaoyang, 111003, Liaoning, P. R. China. E-mail: kahongzqc@163.com; czq0601@sut.edu.cn

$\dagger$ Electronic supplementary information (ESI) available. See DOI: 10.1039/c9ra07798g
In GC, the stationary phase of special selectivity is the key for components, which are to be determined, to realize highefficiency separation..$^{20,21}$ Calix[6]arene features high recognition ability and physicochemical stability and can be good candidates as stationary phases in chromatography. Although calix[6]arene are potentially as useful as other host molecules in chromatographic separation, only a few publications are available. ${ }^{22-28}$ This may be mainly due to their high melting point and poor solubility, which limit the researches and applications of calix[6]arene in chromatography. In chromatographic separation, Zeng et al. reported $p$-tert-butylcalix[6]-1,4-crown-4 and $p$ tert-butylcalix[6]arene bonded silica stationary phase for capillary electrochromatography. ${ }^{23}$ They demonstrated that calix[6] arene stationary phases have high selectivity for the separation of aromatic isomers. Feng et al. reported a calix[6]arene bonded silica gel in liquid chromatography. ${ }^{26}$ The results evidenced the high resolving ability of the calix[6]arene stationary phase for nucleosides and bases. Cardinael et al. studied the incorporation of calix[6]arene derivatives into sol-gels for the preparation of stationary phases for gas chromatography (GC).$^{28}$ Park et al. reported the preparation of A,C- and A,D-bridged calix[6]arene, and the application in capillary GC with OV-1701 for the separation of positional isomers. ${ }^{29} \mathrm{Xing}$ et al. used those two calix[6] cryptand as GC stationary phases mixed with OV-1701 for the separation of some aromatic compounds. ${ }^{30}$ To the best of our knowledge, only the above three reports using calix[6]arene as GC stationary phases are available. Briefly, the above researches, regardless of different chromatographic methods, demonstrate the potential for using calix[6]arene in chromatographic separation.

Herein, we report the first example of utilizing $p$-tert-butyl(tetradecyloxy)calix[6]arene (C6A-C10, Fig. 1) as stationary phase 


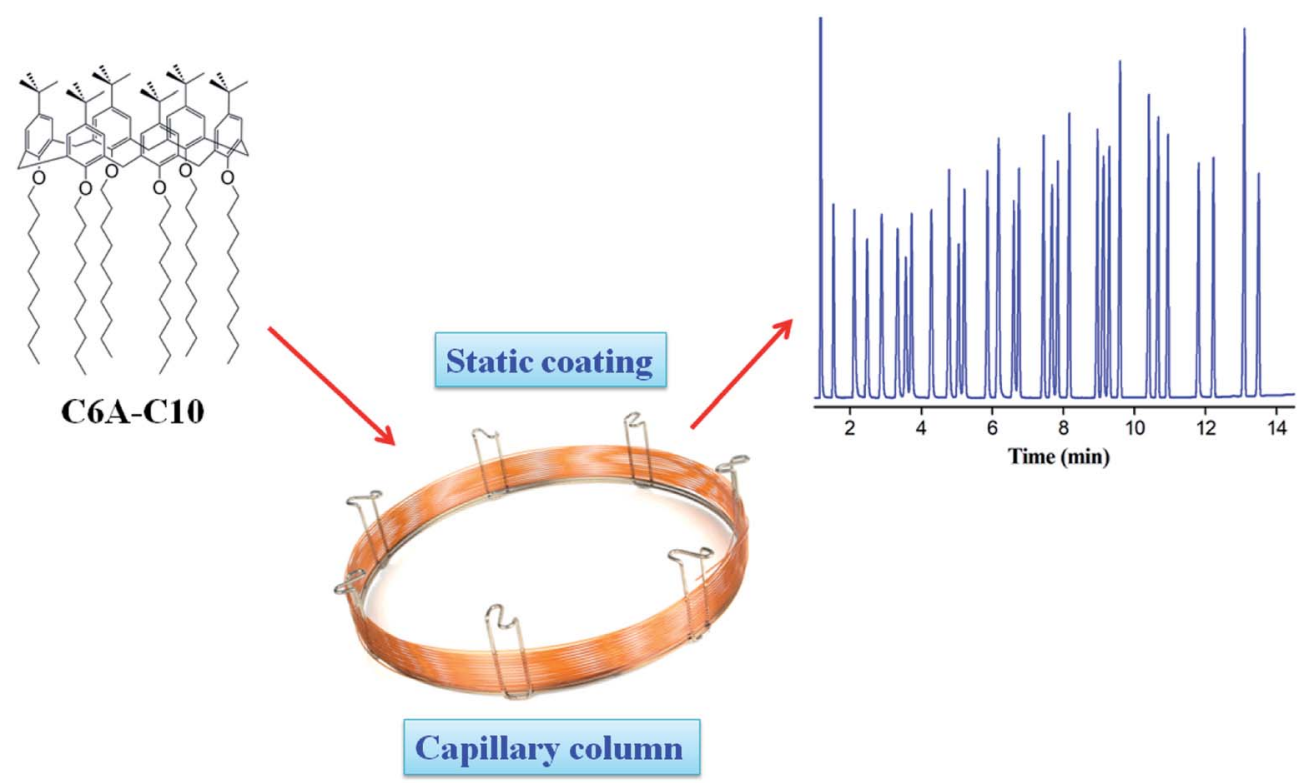

Fig. 1 The C6A-C10 capillary column for GC separation.

for GC separation. Nonpolar long alkyl chains were introduced at the lower rim of the calix[6]arene, which can increase the column efficiency based on improved solubility and filmforming ability of obtained stationary phase. The C6A-C10 capillary column was fabricated by static coating method. Compared with chemically modified or physically mixed stationary phases, C6A-C10 stationary phase can reflect retention behaviors and interaction mechanisms of calixarene-type stationary phases more directly. The C6A-C10 capillary column was characterized for its column efficiency and polarity. Its selectivity and resolving capability were explored by utilizing the mixtures of diverse analytes and their isomers. The column thermal stability were determined and evaluated. And finally the C6A-C10 column was applied for the determination of isomer impurities in real samples.

\section{Experimental}

\subsection{Materials and equipment}

All the reagents and solvents were commercially available without any further purification. All the analytes were analytical grade and dissolved in dichloromethane. 4-tert-Butylcalix[6]arene was purchased from Sun Chemical Technology Co. Ltd (Shanghai, China). Untreated fused-silica capillary tubing $(0.25 \mathrm{~mm}$, i.d. $)$ was purchased from Yongnian Ruifeng Chromatogram Apparatus Co., Ltd. (Hebei, China). The commercial capillary column HP-5 $(10 \mathrm{~m} \times 0.25 \mathrm{~mm}$, i.d., $0.25 \mu \mathrm{m}$ film thickness, $5 \%$ phenyl $95 \%$ dimethyl polysiloxane) was purchased from Agilent Technologies and used as the reference column.

An Agilent 7890A gas chromatograph equipped with a split/ splitless injector, a flame ionization detector (FID) and an autosampler was used for GC separations. All the separations were performed under the following GC conditions: nitrogen of high purity $(99.999 \%)$ as carrier gas, injection port at $250^{\circ} \mathrm{C}$, split ratio at $80: 1$, FID detector at $300{ }^{\circ} \mathrm{C}$. Oven temperature programs for the GC separations were individually provided in the figure captions. ${ }^{1} \mathrm{H}$ NMR spectra were recorded on a Bruker Biospin 400 MHz instrument using TMS as the internal standard. All chemical shifts were reported in ppm. IR spectra were recorded on a Bruker Platinum ART Tensor II FT-IR spectrometer. MALDITOF-MS was recorded on a Bruker BIFLEX III mass spectrometer.

\subsection{Synthesis of the C6A-C10 stationary phase}

C6A-C10 was synthesized according to ref. 31 and 32 4-tertbutylcalix[6]arene $(2.0 \mathrm{~g}, 2.05 \mathrm{mmol})$, sodium hydride $(1.48 \mathrm{~g}$, $61.67 \mathrm{mmol}$ ) and $N, N$-dimethylformamide (DMF) $(30 \mathrm{~mL})$ were added to a $100 \mathrm{~mL}$ round-bottom flask. The mixture was stirred at room temperature for $50 \mathrm{~min}$, then bromodecane $(4.6 \mathrm{~g}, 20.53$ mmol) was added and the solution was heated to $85{ }^{\circ} \mathrm{C}$ and thermostatic $9 \mathrm{~h}$. The yellow thickened solid produced was dissolved with dichloromethane, washed with deionized water $(10 \mathrm{~mL} \times 3)$, dried by anhydrous magnesium sulfate, filtered and concentrated in vacuo. Finally, an orange oil-like crude product was obtained. The crude product was purified by column chromatography $\left(\mathrm{CH}_{2} \mathrm{Cl}_{2}\right.$ : petroleum $\left.=10: 1\right)$ to obtain a white solid (87.23\% yield). Mp 96.6-100.4 ${ }^{\circ} \mathrm{C} ;{ }^{1} \mathrm{H}$ NMR $\left(400 \mathrm{MHz}, \mathrm{CDCl}_{3}\right) \delta: 6.88(\mathrm{~s}, 12 \mathrm{H}), 3.79(\mathrm{~s}, 12 \mathrm{H}), 3.54(\mathrm{~s}, 12 \mathrm{H})$, $1.71(\mathrm{~s}, 12 \mathrm{H}), 1.44(\mathrm{~s}, 12 \mathrm{H}), 1.29(\mathrm{~s}, 72 \mathrm{H}), 1.09(\mathrm{~s}, 54 \mathrm{H}), 0.89(\mathrm{~s}$, $18 \mathrm{H})$; IR (KBr, cm $\left.{ }^{-1}\right)$ : $721.33\left(\mathrm{CH}_{2}\right), 936.87(\mathrm{C}-\mathrm{O}-\mathrm{C}), 1005.46$ (C$\mathrm{O}-\mathrm{C}), 1119.03$ (C-O-C), $1290.24(\mathrm{C}-\mathrm{O}-\mathrm{C}), 1466.72(\mathrm{C}=\mathrm{C})$, 2852.53 $\left(\mathrm{CH}_{2}\right), 2922.03\left(\mathrm{CH}_{2}\right), 2950.21\left(\mathrm{CH}_{3}\right)$. MALDI-TOF MS: $m / z$ calcd for $\mathrm{C}_{126} \mathrm{H}_{204} \mathrm{O}_{6}$ : 1814.6 (100\%); found: 1861.5 [M + $2 \mathrm{Na}]^{+}(100 \%)$.

\subsection{Fabrication of the C6A-C10 capillary column}

The C6A-C10 capillary column was fabricated by static coating method. ${ }^{33-35}$ Before coating, one bare fused-silica capillary 
column (10 $\mathrm{m} \times 0.25 \mathrm{~mm}$, i.d.) was pretreated with a saturated solution of sodium chloride in methanol for the inner surface roughening of the capillary column. Then, the solution was removed and the column was conditioned up to $200{ }^{\circ} \mathrm{C}$ and held for $3 \mathrm{~h}$ under nitrogen atmosphere. After the pretreatment, the column was statically coated with the solution of the C6A-C10 stationary phase in dichloromethane $(0.15 \%, \mathrm{w} / v)$ at room temperature. After the column was filled with the coating solution and sealed at one end, the solvent was evaporated at a steady speed from the other end under vacuum. At last, the column was conditioned from $40^{\circ} \mathrm{C}$ to $160^{\circ} \mathrm{C}$ at $1^{\circ} \mathrm{C} \mathrm{min}{ }^{-1}$ and held at $160{ }^{\circ} \mathrm{C}$ for $7 \mathrm{~h}$ under nitrogen. The as-prepared C6A-C10 column was used for the following work. By using the same procedure, the unmodified calix[6] arene (C6A) column was also obtained.

\section{Results and discussion}

\subsection{Column efficiency and polarity}

To overall evaluate the column efficiency of the C6A-C10 column at varying flow rates, its Golay curve was determined by measuring the height equivalent to a theoretical plate (HETP) of $n$-dodecane at different flow rates at $120{ }^{\circ} \mathrm{C}$, illustrated in Fig. 2a. Notably, it attained the minimum HETP of $0.30 \mathrm{~mm}$ at $16.4 \mathrm{~cm} \mathrm{~s}^{-1}\left(0.4 \mathrm{~mL} \mathrm{~min}^{-1}\right)$, corresponding to the column efficiency of 3293 plates per m. Fig. 2b presents the SEM crosssection images of the C6A-C10 column, confirming its good coating with a thickness of approximately $100 \mathrm{~nm}$ on the capillary column. Polarity of the C6A-C10 stationary phase was characterized by measuring its McReynolds constants using five probe compounds, i.e., benzene $\left(\mathrm{X}^{\prime}\right)$, 1-butanol $\left(\mathrm{Y}^{\prime}\right)$, 2- pentanone $\left(\mathrm{Z}^{\prime}\right)$, 1-nitropropane $\left(\mathrm{U}^{\prime}\right)$ and pyridine $\left(\mathrm{S}^{\prime}\right) .^{36,37}$ As shown in Table 1, its general polarity and average polarity were obtained by the sum and average of these five McReynolds constants, respectively. The GC stationary phase can be classified as non-polar when its average polarity is less than 100 . Therefore, the C6A-C10 stationary phase exhibits nonpolar nature as GC stationary phase and shows comparable average polarity with the commercial HP-5 stationary phase. ${ }^{38}$ Additionally, the Abraham system constants of the C6A-C10 stationary phase were determined at three temperatures $\left(80{ }^{\circ} \mathrm{C}, 100{ }^{\circ} \mathrm{C}\right.$ and $\left.120{ }^{\circ} \mathrm{C}\right)$ and the results were provided in Table $2 .^{39}$ Table S1 (ESI $\dagger$ ) provides the solutes used in this work and their solute descriptors. Table 2 shows that the largest value is $l$, which represents the overall dispersion interaction and cavity formation of the C6A-C10 stationary phase.

\subsection{Separation performance}

Separation performance of the C6A-C10 column was investigated in terms of resolving capability and retention behaviours by utilizing aliphatic analytes, substituted benzenes, Grob test mixture, and positional, structural and cis-/trans-isomers. As shown in Fig. 3a, the mixture of 30 aliphatic analytes including $n$-alkanes, bromoalkanes, esters, ketones, aldehydes, and alcohols was baseline separated with good peak shapes $(R>1.5)$. These aliphatic analytes vary from apolar to polar nature. Among them, the peak pairs such as methyl valerate (peak 3; bp, $128{ }^{\circ} \mathrm{C}$ )/1-bromopentane (peak 4; bp, $130{ }^{\circ} \mathrm{C}$ ), octanal (peak 10; bp, $171{ }^{\circ} \mathrm{C}$ )/methyl heptanoate (peak 11; bp, $172{ }^{\circ} \mathrm{C}$ ) and 1decanol (peak 21; bp, $231{ }^{\circ} \mathrm{C}$ )/2-undecanone (peak 22; bp, 231 ${ }^{\circ} \mathrm{C}$ ) were baseline resolved on the column despite of minor differences between their boiling points. The above results
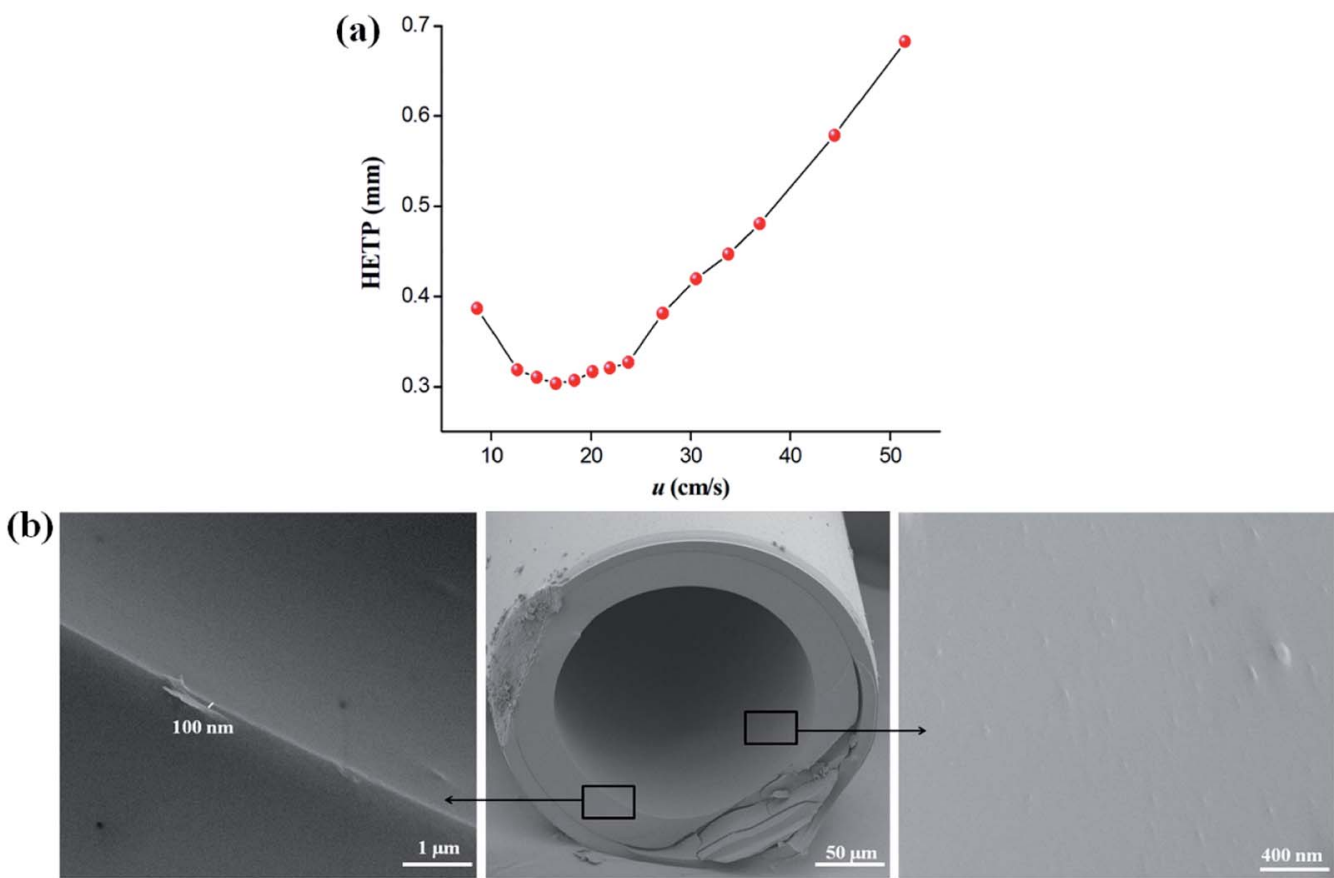

Fig. 2 (a) Golay curve of the C6A-C10 column determined by $n$-dodecane at $120^{\circ} \mathrm{C}$, and the carrier gas is nitrogen; (b) the cross-section SEM images on the inner wall surface and the coating thickness of the C6A-C10 column. 
Table 1 McReynolds constants of the C6A-C10 and commercial HP-5 column $^{a}$

\begin{tabular}{lrrrrrll}
$\begin{array}{l}\text { Stationary } \\
\text { phases }\end{array}$ & $\mathrm{X}^{\prime}$ & $\mathrm{Y}^{\prime}$ & $\mathrm{Z}^{\prime}$ & $\mathrm{U}^{\prime}$ & $\mathrm{S}^{\prime}$ & General polarity & Average \\
\hline C6A-C10 & 41 & 124 & 73 & 115 & 92 & 445 & 89 \\
HP-5 & 30 & 72 & 62 & 96 & 65 & 325 & 65
\end{tabular}

${ }^{a} \mathrm{X}^{\prime}$, Benzene; $\mathrm{Y}^{\prime}$, 1-butanol; $\mathrm{Z}^{\prime}$, 2-pentanone; $\mathrm{U}^{\prime}$, 1-nitropropane; $\mathrm{S}^{\prime}$, pyridine. Temperature: $120{ }^{\circ} \mathrm{C}$.

demonstrated the high resolving capability of the C6A-C10 column for aliphatic analytes of broad polarity range. Regarding the elution order, the C6A-C10 stationary phase retained all the analytes by the order of their boiling points. This result suggested the possible contribution of the six decyl alkyl chains to the retention of the C6A-C10 stationary phase. The elution of the aliphatic analytes of diverse polarities basically follows the order of their van der Waals surface areas, the larger surface area, and the longer retention on the C6A-C10 column. This finding also suggests the distinguishing capability of the C6A-C10 stationary phase for analytes with linear owing to its unique architecture and shape selectivity.

In the light of the 3D aromatic cavity of the C6A-C10 stationary phases, its separation capability for aromatic analytes was quite worth exploring. Accordingly, another mixture mainly containing substituted benzenes was utilized for the investigation. As shown in Fig. 3b, the mixture containing 21 different di- and tri-substituted benzenes was effectively separated $(R>1.5)$ and sharp symmetrical peaks were obtained on C6A-C10 column. The outstanding resolving capability of the C6A-C10 column for aromatic analytes can be ascribed to the specific $\pi-\pi$ stacking interactions between them. In summary, the above results demonstrated the high selectivity and resolving ability of C6A-C10 capillary column for diverse types of analytes varying from nonpolar to polar and from aliphatic to aromatic compounds and showed its potential in GC separations. Regarding the driving forces for the separations, the van der Waals interactions mainly contribute to the resolution of

Table 2 The Abraham system constants $( \pm s d)$ of the C6A-C10 stationary phase ${ }^{a}$

\begin{tabular}{|c|c|c|c|c|c|c|c|c|c|c|}
\hline$T\left({ }^{\circ} \mathrm{C}\right)$ & $e$ & $s$ & $a$ & $b$ & $l$ & $c$ & $R^{2}$ & $\mathrm{SE}$ & $F$ & $N$ \\
\hline 80 & $0.003(0.005)$ & $0.467(0.034)$ & $0.428(0.072)$ & $-0.216(0.070)$ & $0.554(0.017)$ & $-2.263(0.076)$ & 0.993 & 0.039 & 609 & 26 \\
\hline 100 & $-0.023(0.006)$ & $0.464(0.034)$ & $0.686(0.077)$ & $-0.482(0.075)$ & $0.454(0.017)$ & $-2.058(0.076)$ & 0.990 & 0.040 & 406 & 25 \\
\hline
\end{tabular}

${ }^{a} n$, Number of solutes used in the model; $R^{2}$, coefficient of determination; $F$, Fisher's factor; SE, standard error of the estimate.
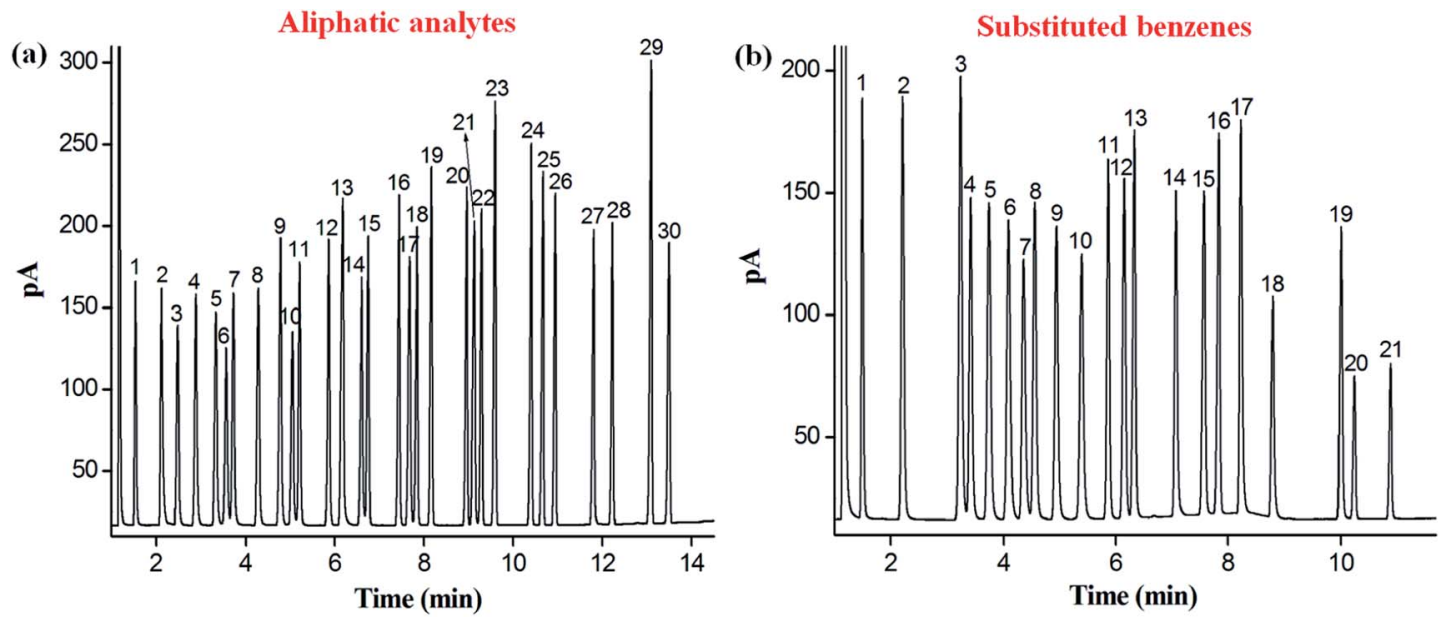

Fig. 3 Separations of aliphatic analytes (a) and substituted benzenes (b) on the C6A-C10 column. Peaks for (a): (1) 2-pentanone, (2) 1-pentanol, (3) methyl valerate, (4) 1-bromopentane, (5) 2-heptanone, (6) heptaldehyde, (7) methyl hexanoate, (8) 1-bromohexane, (9) 2-octanone, (10) octanal, (11) methyl heptanoate, (12) 1-bromoheptane, (13) 1-bromooctane, (14) nonanal, (15) methyl octanoate, (16) 1-bromooctane, (17) 1nonanol, (18) 2-decanone, (19) $n$-dodecane, (20) 1-bromononane, (21) 1-decanol, (22) 2-undecanone, (23) $n$-tridecane, (24) 1-bromodecane, (25) 2-dodecanone, (26) $n$-tetradecane, (27) 1-dodecanol, (28) n-pentadecane, (29) 1-bromododecane, (30) $n$-hexadecane. Peaks for (b): (1) benzene, (2) toluene, (3) ethylbenzene, (4) p-xylene, (5) o-xylene, (6) cumene, (7) 3,4,5-trifluorobenzaldehyde, (8) propylbenzene, (9) 1,3,5trimethylbenzene, (10) sec-butylbenzene, (11) 1,4-dichlorobenzene, (12) butylbenzene, (13) acetophenone, (14) 2,6-dimethylphenol, (15) 2ethylbenzaldehyde, (16) 1,3,5-trichlorobenzene, (17) 2,3-dimethylphenol, (18) 2-cyanobenzaldehyde, (19) carvacrol, (20) 3,4-dicholorobenzaldehyde, (21) 3-nitrobenzaldehyde. Temperature program: $40^{\circ} \mathrm{C}$ for $1 \mathrm{~min}$ to $160{ }^{\circ} \mathrm{C}$ at $10^{\circ} \mathrm{C} \mathrm{min}^{-1}$ for (a) and (b), and held at $160{ }^{\circ} \mathrm{C}$ for $3 \mathrm{~min}$. Flow rate: $23.7 \mathrm{~cm} \mathrm{~s}^{-1}\left(0.6 \mathrm{~mL} \mathrm{~min}^{-1}\right)$. 
the aliphatic analytes while the $\pi-\pi$ stacking interactions play a major role in the separation of the aromatic analytes.

The Grob mixture is a well-recognized diagnostic mixture for the evaluation of the overall chromatographic performance and column activity of a GC column. In the mixture composed of 12 probing analytes, 2,3-butanediol, 2-ethylhexanoic acid and dicyclohexylamine are tough to be well resolved from their adjacent analytes due to their high sensitivity to possible active sites on the column. As shown in Fig. 4, C6A-C10 column achieved good resolution and peak shape for almost all the analytes whereas the commercial HP-5 column coeluted the analytes of $n$-undecane/n-nonanal/2,6-dimethylphenol (peak 5/4/6) and dicyclohexylamine/methyl undecanoate (peak 11/10). These results indicate that the inertness of the C6A-C10 column satisfies the requirements of gas chromatography analysis. Moreover, C6A-C10 showed longer retention for $n$-undecane and dicyclohexylamine. The prolonged retention for these analytes may derive from its stronger dispersion and $\pi-\pi$ interactions originating from its unique $3 \mathrm{D}$ aromatic structure with long alkyl chains. To confirm the effect of the alkyl chains attached to calix[6]arene on chromatographic separation, the separation performance of the C6A-C10 column was investigated by Grob mixture in comparison with the C6A column. As shown in Fig. 4, C6A-C10 column showed good peak shape for most of the analytes that are liable to severe peak tailing on the C6A column. Notably, in contrast to the C6A column, the C6AC10 column exhibited reversal elution for the analyte pairs of 1-octanol/n-nonanal/n-undecane (peaks 3/4/5) and 2-ethylhexanoic acid/methyl decanoate (peaks 7/9), suggesting the comparatively weaker H-bonding ability of the C6A-C10 stationary phase for the alcohol and acid. This may result from the H-bonding interactions of the C6A column with $\mathrm{H}$ bonding donors due to its residual silanol groups. Thus, the alkyl chains were linked to the calix[6] arene to improve the chromatographic peak shape based on good film-forming ability of obtained stationary phase.

Furthermore, the separation performance of the C6A-C10 column was investigated by a wide variety of isomer mixtures.
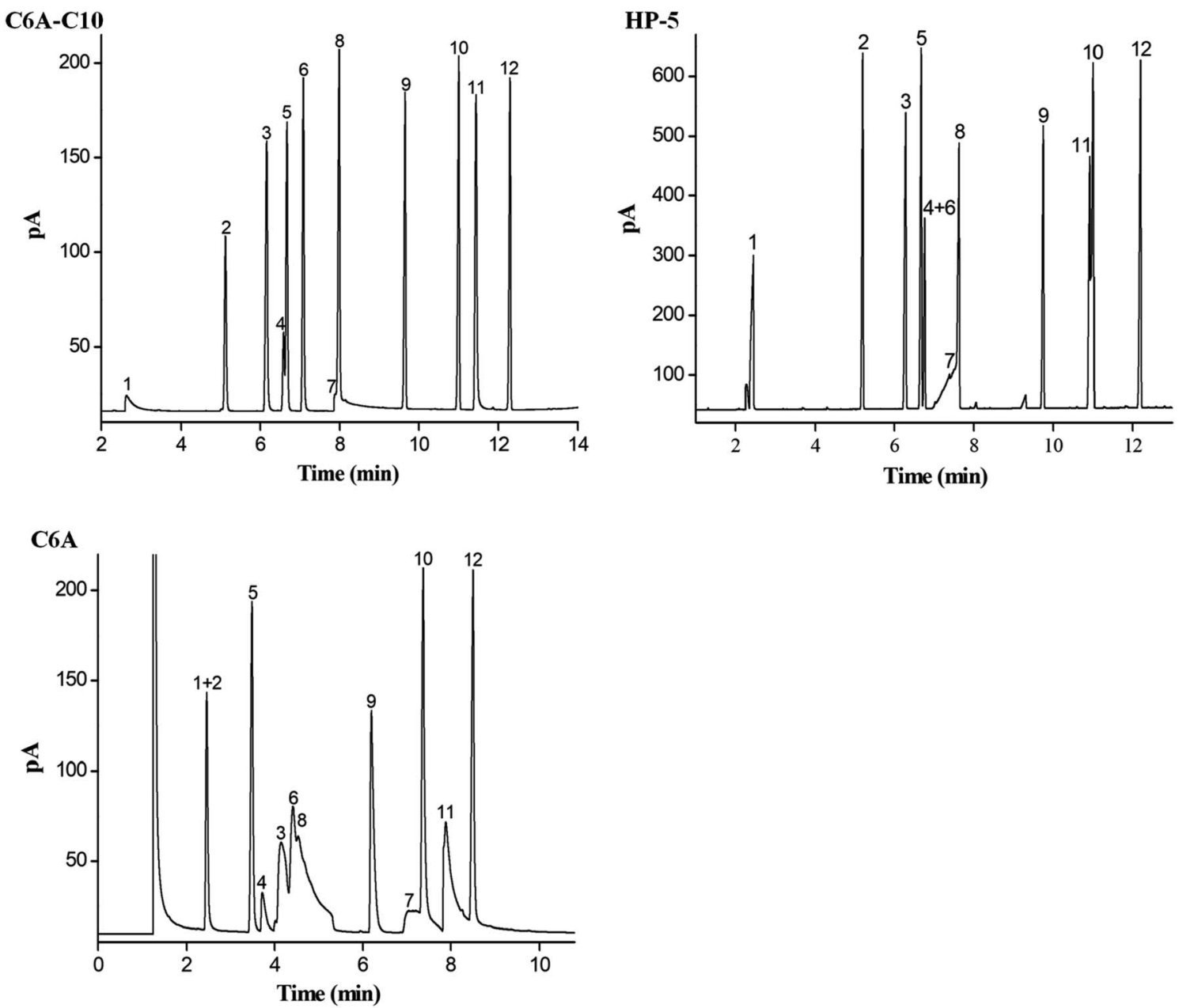

Fig. 4 Separations of the Grob mixture on the C6A-C10 column in comparison to the HP-5 and C6A columns. Peaks: (1) 2,3-butanediol, (2) ndecane, (3) 1-octanol, (4) n-nonanal, (5) n-undecane, (6) 2,6-dimethylphenol, (7) 2-ethylhexanoic acid, (8) 2,6-dimethylaniline, (9) methyl decanoate, (10) methyl undecanoate, (11) dicyclohexylamine, (12) methyl dodecanoate. Temperature program on C6A-C10, HP-5 and C6A columns: $40{ }^{\circ} \mathrm{C}$ for $1 \mathrm{~min}$ to $160^{\circ} \mathrm{C}$ at $10^{\circ} \mathrm{C} \mathrm{min}^{-1}$, and held at $160{ }^{\circ} \mathrm{C}$ for $3 \mathrm{~min}$. Flow rate: $23.7 \mathrm{~cm} \mathrm{~s}^{-1}\left(0.6 \mathrm{~mL} \mathrm{~min}{ }^{-1}\right)$. 

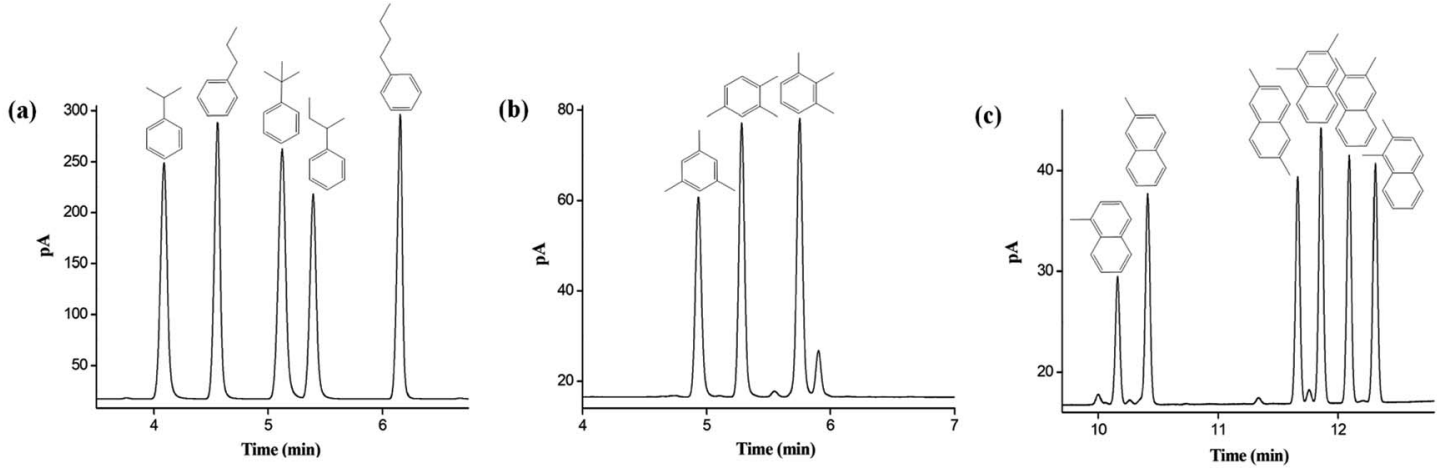

(d)
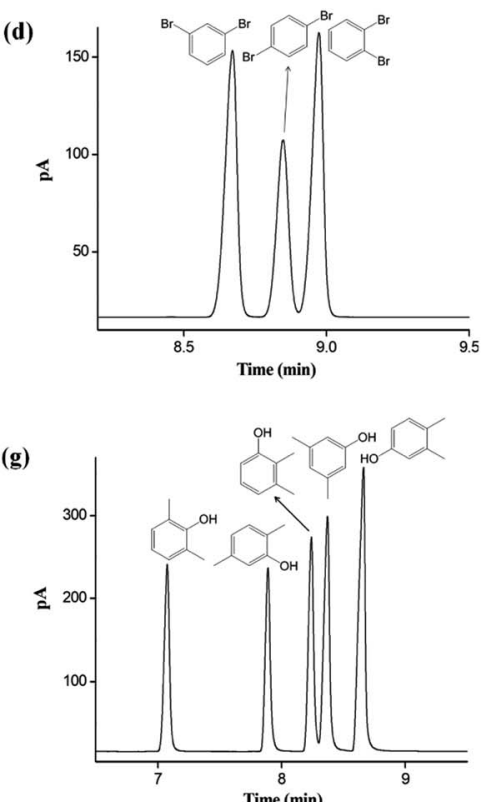
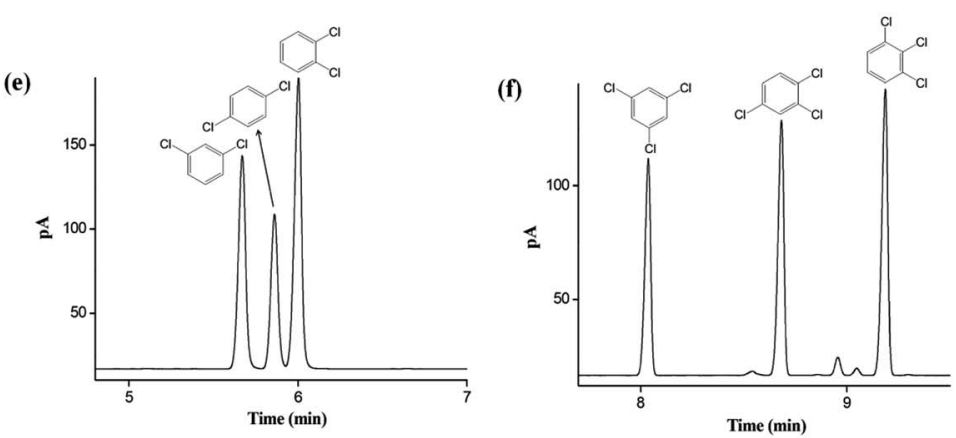

Fig. 5 Separations of isomer mixtures of (a) propylbenzene and butylbenzene, (b) trimethylbenzene, (c) methylnaphthalene and dimethylnaphthalene, (d) dibromobenzene, (e) dichlorobenzene, (f) trichlorobenzene, and (g) xylenol on the C6A-C10 column. Temperature program: $40{ }^{\circ} \mathrm{C}$ for $1 \mathrm{~min}$ to $160^{\circ} \mathrm{C}$ at $10^{\circ} \mathrm{C} \mathrm{min}-1$ for (a), (b), (e), (f) and (g). Temperature program: $40{ }^{\circ} \mathrm{C}$ for $1 \mathrm{~min}^{\circ} 160^{\circ} \mathrm{C}$ at $10^{\circ} \mathrm{C} \mathrm{min}{ }^{-1}$ for (c),

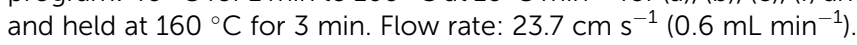

As shown in Fig. 5a-g, the C6A-C10 column achieved baseline resolution $(R>1.5)$ of the aromatic isomers from nonpolar to polar nature with sharp peaks. Fig. $5 \mathrm{a}-\mathrm{c}$ exhibits the separations of alkylated benzenes and naphthalenes isomers, such as propylbenzene and butylbenzene (Fig. 5a), trimethylbenzene (Fig. 5b), methylnaphthalene and dimethylnaphthalene (Fig. 5c). Also, C6A-C10 column achieved high resolution of the halogenated benzene isomers, including dibromobenzene (Fig. 5d), dichlorobenzene (Fig. 5e), and trichlorobenzene (Fig. 5f). All the isomers, especially the critical pairs of $m-/ p$ dibromobenzene and $m$-/ $p$-dichlorobenzene with bp difference less than $1{ }^{\circ} \mathrm{C}$, were baseline resolved $(R>1.5)$. It is noteworthy that phenol isomers are tough analytes prone to peak tailing in GC separations. As shown in Fig. 5g, C6A-C10 column exhibited high resolution for the xylenol isomer mixtures with sharp symmetrical peaks. The high retention for the aromatic isomers can be ascribed to the unique aromatic skeleton of the calix[6] arene stationary phase with the 3D cavity, which may providing slightly different $\pi-\pi$ interactions with the analytes.

The above findings on its high resolving ability suggested the good potential of the C6A-C10 column for separations of analytes of high similarity in physicochemical properties. Hence, we made the investigations on its capability for separations of cis-/trans-isomers consist of aliphatic and aromatic analytes. Fig. 6 presents the separation of twelve isomer mixtures on the C6A-C10 column, including alkanes, alkenes, furans, alcohols, aldehydes and naphthalenes. As shown, the C6A-C10 column achieved baseline resolution for all the isomers, demonstrating its good distinguishing capability for analytes of high similarity. Undoubtedly, the combination of the 3D aromatic cavity with linear alkyl chain complements their advantages and makes a great difference in promoting the resolving capability for analytes of close nature through the synergistic effect of the molecular interactions described previously. 
(a)

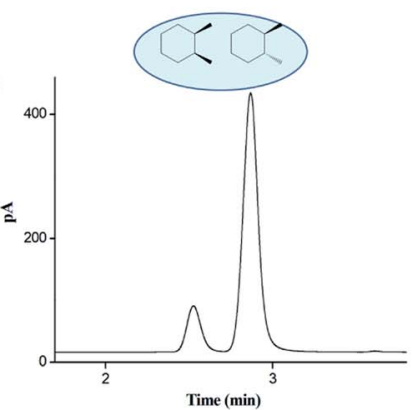

(d)

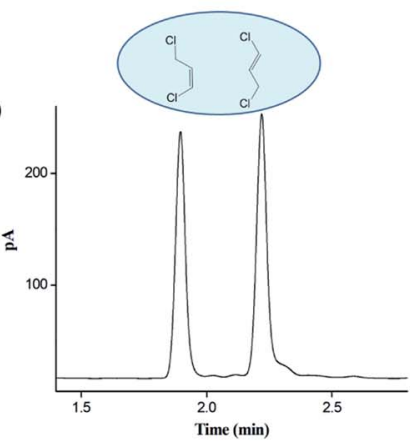

(g)

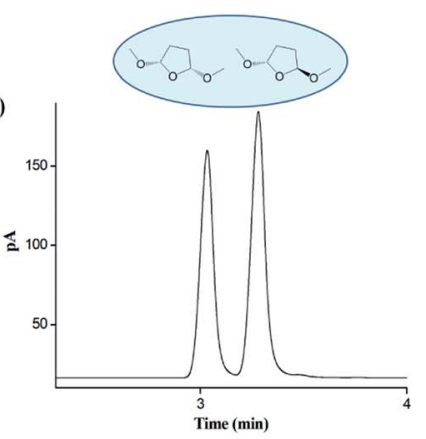

(j)

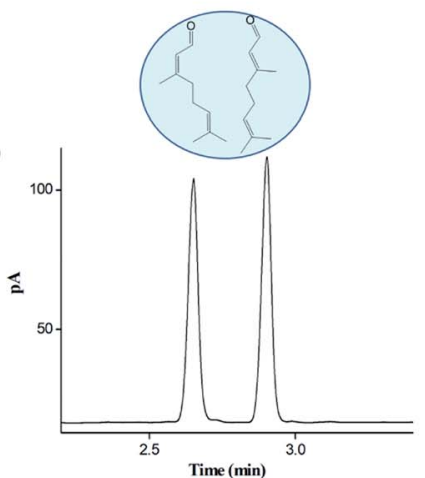

(b)

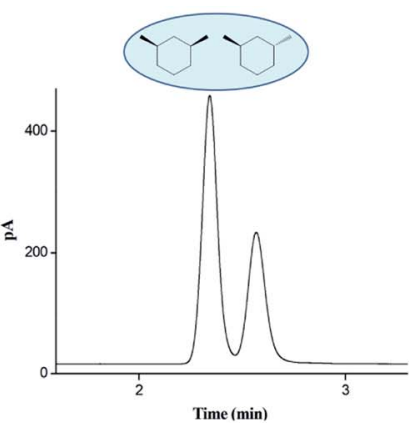

(e)

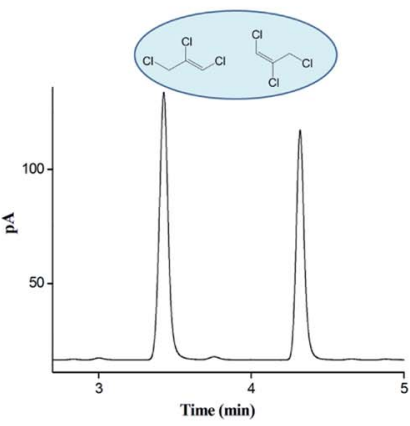

(h)

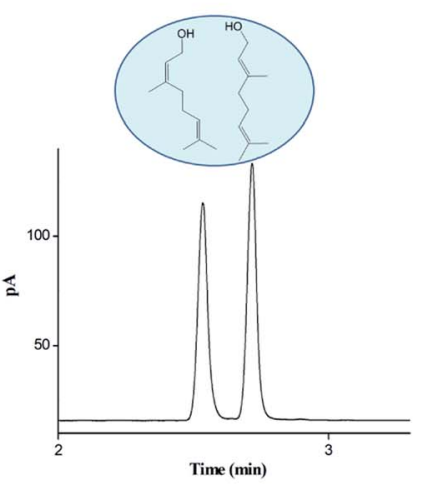

(k)

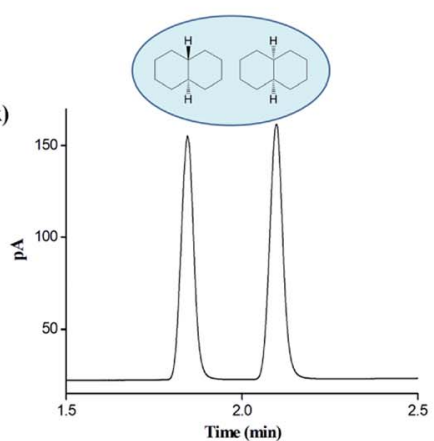

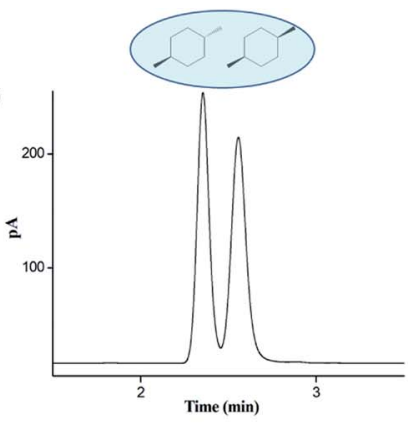

(f)

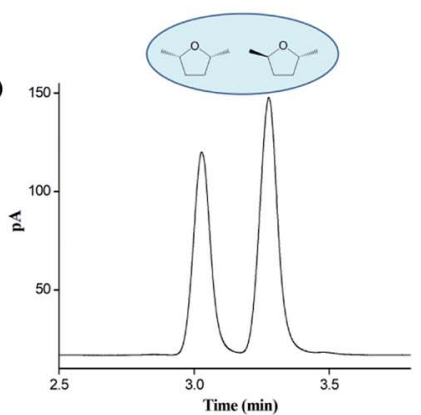

(i)

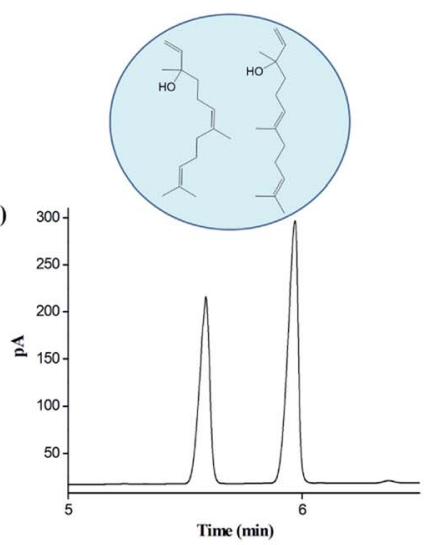

Fig. 6 Separations cis-/trans-isomers of (a) 1,2-dimethylcyclohexane, (b) 1,3-dimethylcyclohexane, (c) 1,4-dimethylcyclohexane, (d) 1,3dichloropropene, (e) 1,2,3-trichloropropene, (f) 2,5-dimethyltetrahydrofuran, (g) 2,5-dimethoxytetrahydrofuran, (h) nerol/geraniol, (i) nerolidol, (j) citral, and (k) decahydronaphthalene on the $\mathrm{C} 6 \mathrm{~A}-\mathrm{C} 10$ column. Temperature program: $40^{\circ} \mathrm{C}$ for 1 min to $90^{\circ} \mathrm{C}$ at $10^{\circ} \mathrm{C} \mathrm{min}{ }^{-1}$ for $(a-g) ; 100{ }^{\circ} \mathrm{C}$ to $160{ }^{\circ} \mathrm{C}$ at $10^{\circ} \mathrm{C} \mathrm{min}^{-1}$ for (h)-(k); $100{ }^{\circ} \mathrm{C}$ to $160{ }^{\circ} \mathrm{C}$ at $10^{\circ} \mathrm{C} \mathrm{min}^{-1}$ for (i), and held at $160{ }^{\circ} \mathrm{C}$ for $1 \mathrm{~min}$. Flow rate: $23.7 \mathrm{~cm} \mathrm{~s}{ }^{-1}\left(0.6 \mathrm{~mL} \mathrm{~min}^{-1}\right.$ ).

3.3. Column minimum allowable operating temperature, thermal stability and repeatability

The minimum allowable operating temperature (MiAOT) was defined as the temperature where the column efficiency drops down to half of its original value at elevated temperatures. ${ }^{\mathbf{4 0}}$ The MiAOT of the C6A-C10 column was determined by naphthalene over the temperature range of $40-140{ }^{\circ} \mathrm{C}$ at a flow rate of 1 $\mathrm{mL} \mathrm{min}^{-1}$. As shown in Fig. 7a, the column efficiency decreased 
gradually with the reduction of temperature and the half column efficiency occurred at about $40{ }^{\circ} \mathrm{C}$, indicating that it is the MiAOT for GC separation.

Column thermal stability was evaluated by the isomer mixtures of alkylbenzenes and halobenzenes after the column was conditioned up to each of the temperatures $\left(160{ }^{\circ} \mathrm{C}\right.$ to $240{ }^{\circ} \mathrm{C}$ in increments of $20^{\circ} \mathrm{C}$ ) for $2 \mathrm{~h}$, respectively. After each cycle of column conditioning, the sample was run on the conditioned column. Fig. $7 \mathrm{~b}$ shows that the retention times of these isomers remained almost unchanged with the RSD values of $0.9-1.4 \%$ over the temperature range. The above results suggest that the C6A-C10 column can be operated under $240{ }^{\circ} \mathrm{C}$ with good separation performance. In addition, column bleeding profile of the $\mathrm{C} 6 \mathrm{~A}-\mathrm{C} 10$ column was determined by programming column from $40{ }^{\circ} \mathrm{C}$ to $300{ }^{\circ} \mathrm{C}$ at $3^{\circ} \mathrm{C} \mathrm{min}^{-1}$ (Fig. 7c). The C6A-C10 column was used up to its maximum allowable operating temperature of $240{ }^{\circ} \mathrm{C}$, wherein the increase in background signal measured is $15 \mathrm{pA}^{\mathbf{4 1 , 4 2}}$ Thus, this temperatures is recommended as the maximum operational temperature for practical use.

Column repeatability and reproducibility of the C6A-C10 column was determined by separating the aromatic isomers, including propylbenzene, butylbenzene and trimethylbenzene. The evaluation was performed by the relative standard deviation values (RSD\%) of their retention times in the run-to-run and day-to-day repeatability and column-to-column reproducibility. Table 3 shows the results with the RSD values in the range of $0.01-0.05 \%$ for run-to-run, $0.09-0.16 \%$ for day-to-day and 2.39$4.69 \%$ for column-to-column, demonstrating their good column repeatability and reproducibility.

\subsection{Applications for the determination of isomer impurities inreal samples}

The C6A-C10 capillary column was employed to determine the possible isomer impurities in commercial reagent samples Fig. 8 provides the results for the samples of cis-decahydronaphthalene, trans-decahydronaphthalene, iso-propylbenzene and 1,2,4-trichlorobenzene. As indicated, the C6AC10 column well resolved the isomer impurities from the main component in each sample. For cis-decahydronaphthalene, the contents of the major component and the isomer impurity were $98.04 \%$ and $1.26 \%$, respectively. For trans-decahydronaphthalene, the corresponding contents were $99.38 \%$ and $0.44 \%$. For iso-propylbenzene, the corresponding contents were $99.10 \%$ and $0.11 \%$. For $1,2,4$-trichlorobenzene, the corresponding contents were $99.17 \%$ and $0.29 \%$. The results were in good agreement with the label purity for each sample.
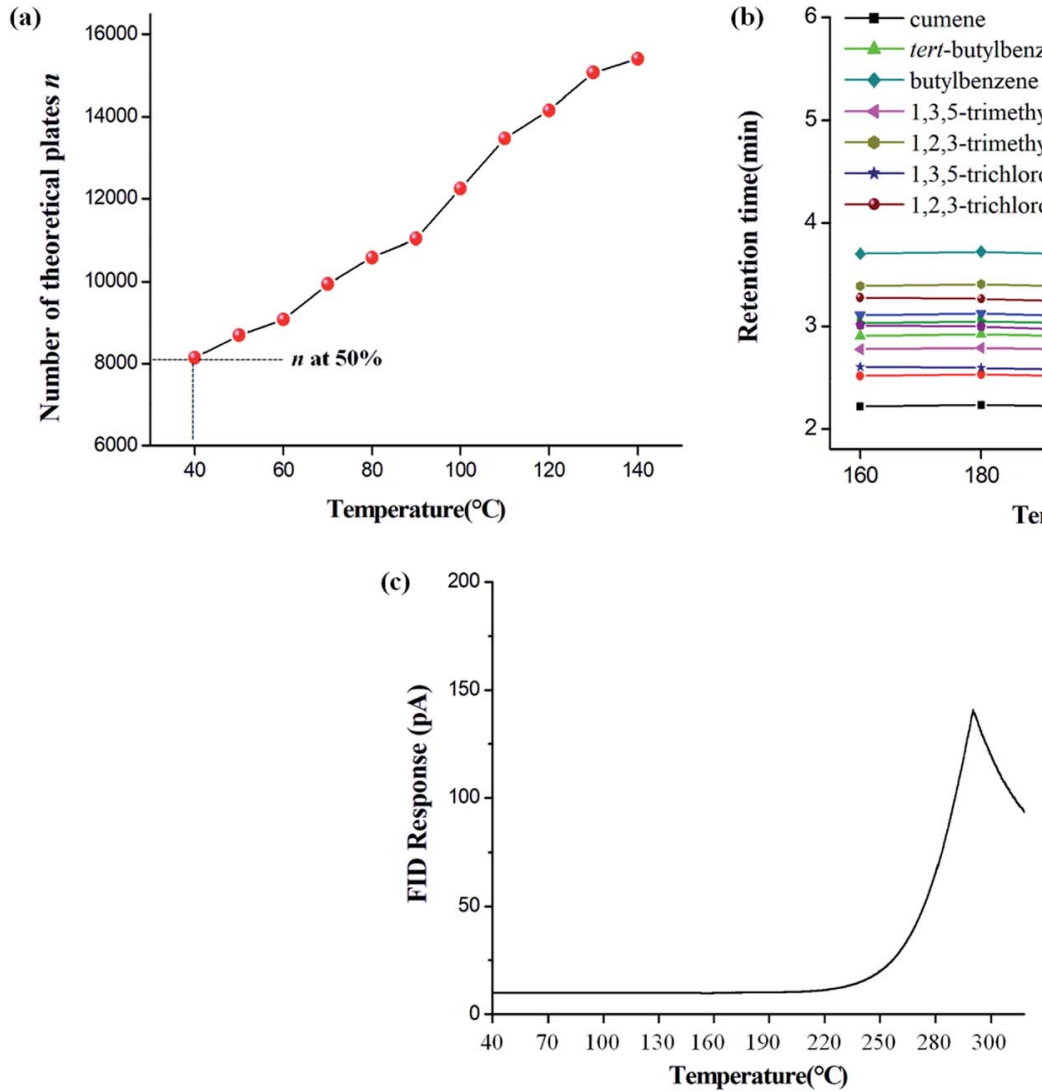

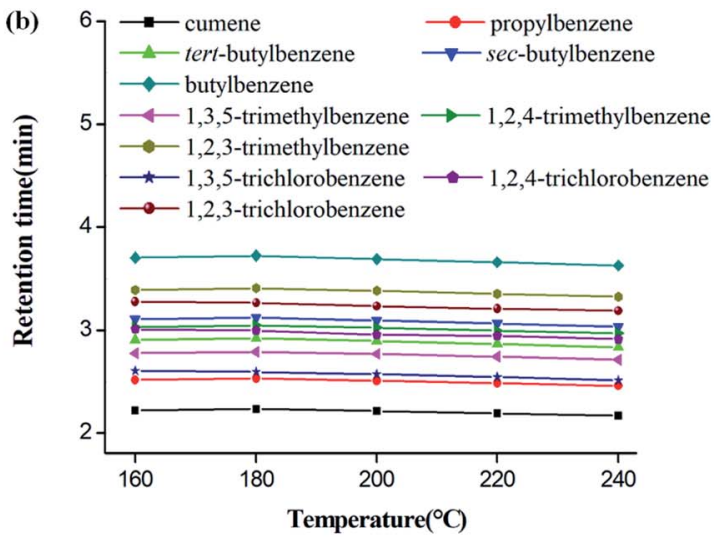

Fig. 7 Determination of the minimum allowable operating temperature (MiAOT) was determined by naphthalene (a), the thermal stability (b) and bleed temperature (c) for the C6A-C10 column. Temperature program (Fig. $8 \mathrm{~b}$ ): $50{ }^{\circ} \mathrm{C}$ to $90{ }^{\circ} \mathrm{C}$ at $10^{\circ} \mathrm{C}$ min $^{-1}$ for propylbenzenes, butylbenzenes, and trimethylbenzenes; $85^{\circ} \mathrm{C}$ to $140{ }^{\circ} \mathrm{C}$ at $10^{\circ} \mathrm{C} \mathrm{min}{ }^{-1}$ for trichlorobenzenes. Flow rate: $36.9 \mathrm{~cm} \mathrm{~s}^{-1}\left(1 \mathrm{~mL} \mathrm{~min}^{-1}\right)$. 
Table 3 Repeatability and reproducibility of the C6A-C10 column on the retention times ( $t_{R}$, min) of the indicated isomers

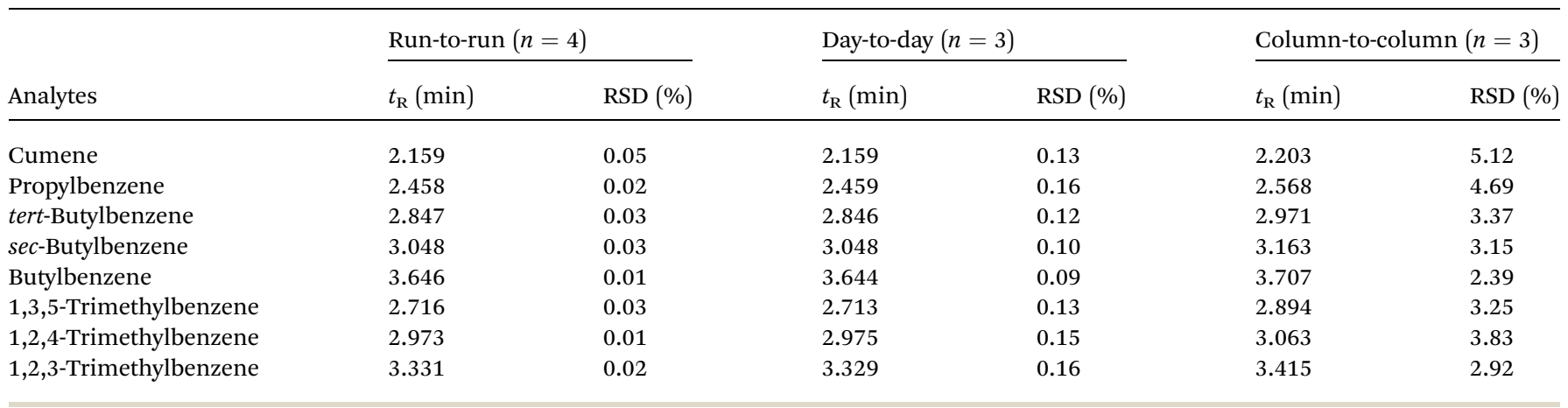

(a)

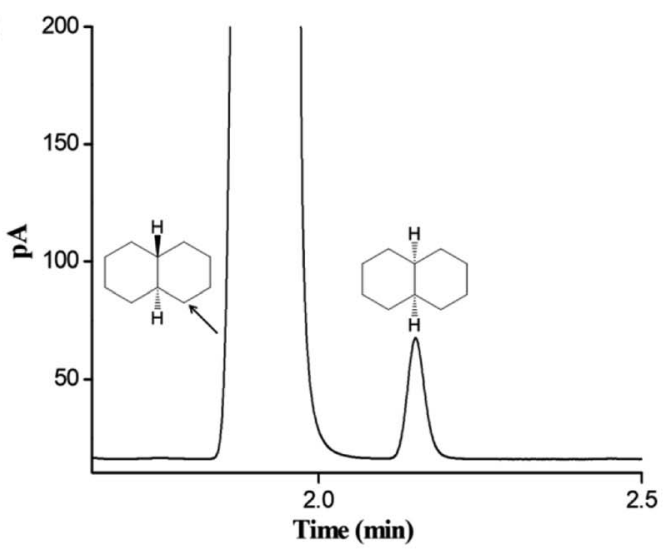

(c)

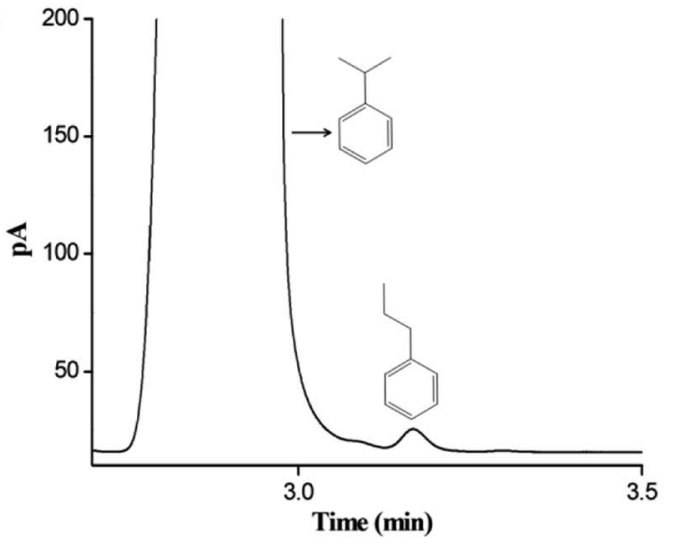

(b)

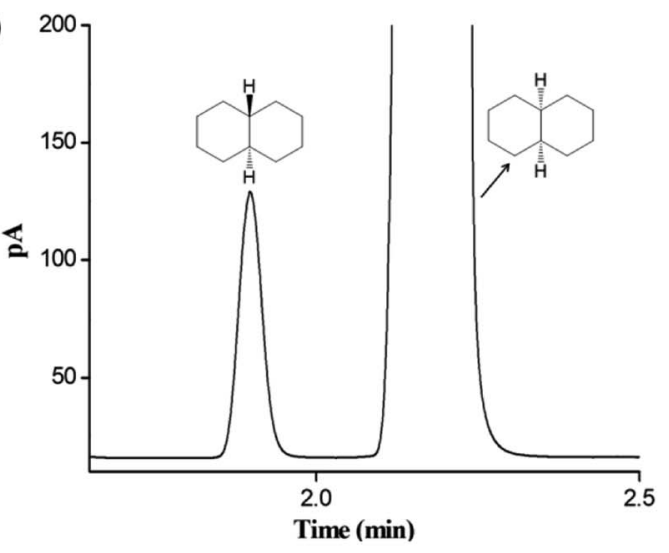

(d)

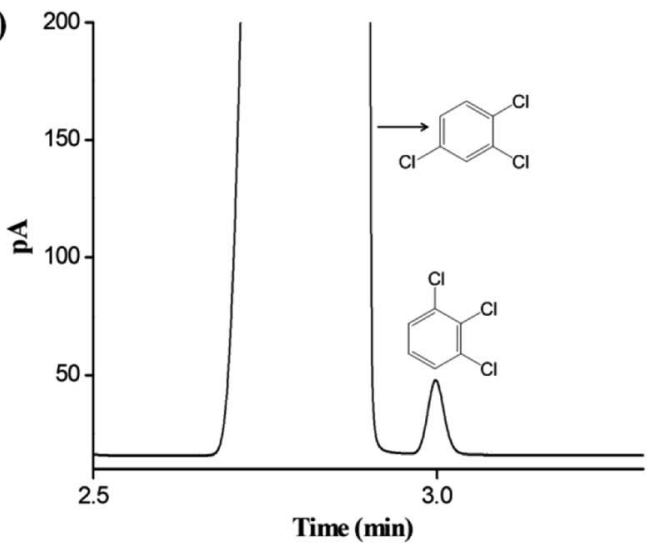

Fig. 8 Applications of the C6A-C10 column for the determination of minor isomer impurities in the real samples of cis-decahydronaphthalene (a), trans-decahydronaphthalene (b), iso-propylbenzene (c) and 1,2,4-trichlorobenzene (d), respectively. Temperature program: $100{ }^{\circ} \mathrm{C}$ to $160{ }^{\circ} \mathrm{C}$ at $10^{\circ} \mathrm{C} \mathrm{min}^{-1}$ for (a) and (b); $50{ }^{\circ} \mathrm{C}$ to $90^{\circ} \mathrm{C}$ at $10^{\circ} \mathrm{C} \mathrm{min}^{-1}$ for (c) and (d). Flow rate: $23.7 \mathrm{~cm} \mathrm{~s}^{-1}\left(0.6 \mathrm{~mL} \mathrm{~min}^{-1}\right.$ ).

\section{Conclusion}

This work presents the first example of exploring C6A-C10 as stationary phase for GC separations. The C6A-C10 stationary phase has unique 3D structure and favorable physicochemical features. As demonstrated, the C6A-C10 stationary phase exhibits good separation performance and column inertness for different types of analytes and their isomers (aliphatic/ aromatic, nonpolar/polar). Its high distinguishing capability can be mainly credited to the integrated effect of $\pi-\pi$ and van der Waals interactions. Moreover, it has good thermal stability and shows promise for practical applications. The present work demonstrates the feasibility of the C6A-C10 stationary phase for GC separations and provides a research basis for exploring other calix[6]arene-based materials in separation science.

\section{Conflicts of interest}

There are no conflicts to declare. 


\section{Acknowledgements}

The work was supported by the National Natural Science Foundation of China (No. 21705072), Key Science and Research Project for Colleges and Universities in Henan Province (No. 17A150039), Natural Science Foundation of Liaoning Province (20180550016).

\section{References}

1 S. Shinkai, Tetrahedron, 1993, 49, 8933-8968.

2 H. J. Kim, M. H. Lee, L. Mutihac, J. Vicens and J. S. Kim, Chem. Soc. Rev., 2012, 41, 1173-1190.

3 N. Y. Edwards and A. L Possanza, Supramol. Chem., 2013, 25, 446-463.

4 N. Bregović, N. Cindro, L. Frkanec and V. Tomišić, Supramol. Chem., 2016, 28, 608-615.

5 S. E. Matthews and P. D. Beer, Supramol. Chem., 2005, 17, 411-435.

6 M. Yilmaz and S. Erdemir, Turk. J. Chem., 2013, 37, 558-585.

7 M. D. Rosa, P. L. Manna, A. Soriente, C. Gaeta, C. Talotta and P. Neri, RSC Adv., 2016, 6, 91846-91851.

8 D. M. Homden and C. Redshaw, Chem. Rev., 2008, 108, 50865130.

9 M. Schulz, A. Gehl, J. Schlenkrich, H. A. Schulze, S. Zimmermann and A. Schaate, Angew. Chem., Int. Ed., 2018, 57, 12961-12965.

10 J. S. Kim and D. T. Quang, Chem. Rev., 2007, 107, 3780-3799. 11 O. Gezici and M. Bayrakci, J. Inclusion Phenom. Macrocyclic Chem., 2015, 83, 1-18.

12 K. Kurzątkowska, S. Sayin, M. Yilmaz, H. Radecka and J. Radecki, Sens. Actuators, B, 2015, 218, 111-121.

13 K. Hu, J. Y. Qiao, X. X. Wu, H. X. Yang, Y. J. Huang and S. S. Zhang, Microchem. J., 2018, 143, 39-46.

14 W. F. Zhang, Y. H. Zhang, Y. M. Zhang, C. Lan, Y. Miao, Z. F. Deng, X. Ba, W. D. Zhao and S. S. Zhang, Talanta, 2019, 193, 56-63.

15 B. Mokhtari and K. Pourabdollah, J. Inclusion Phenom. Macrocyclic Chem., 2012, 73, 1-15.

16 V. Zanichelli, G. Ragazzon, G. Orlandini, M. Venturi, A. Credi, S. Silvi, A. Arduini and A. Secchi, Org. Biomol. Chem., 2017, 15, 6753-6763.

17 A. Dawn, A. Eisenhart, M. Mirzamani, T. L. Beck and H. Kumari, Chem. Commun., 2018, 54, 7131-7134.

18 R. Lavendomme, F. Desroches, S. Moerkerke, F. Topić, J. Wouters, K. Rissanen, M. Luhmer and I. Jabin, Supramol. Chem., 2019, DOI: 10.1080/ 10610278.2019.1679374.
19 O. Gezici and M. Bayrakci, J. Inclusion Phenom. Macrocyclic Chem., 2015, 83, 1-18.

20 G. Boczkaj, M. Momotko, D. Chruszczyk, A. Przyjazny and M. Kamiński, J. Sep. Sci., 2016, 39, 2527-2536.

21 G. Boczkaj, M. Momotko, A. Przyjazny and M. Kamiński, J. Sep. Sci., 2016, 39, 748-755.

22 Y. X. Xiao, X. Z. Xiao, Y. Q. Feng, Z. H. Wang and S. L. Da, Talanta, 2002, 56, 1141-1151.

23 Z. R. Zeng, C. H. Xie, H. B. Li, H. M. Han and Y. Y. Chen, Electrophoresis, 2002, 23, 1272-1278.

24 W. Xu, J. S. Li, Y. Q. Feng, S. L. Da, Y. Y. Chen and X. Z. Xiao, Chromatographia, 1998, 48, 245-250.

25 Y. X. Xiao, X. Z. Xiao, Y. Q. Feng, Z. H. Wang and S. L. Da, J. Liq. Chromatogr. Relat. Technol., 2001, 24, 2925-2942.

26 L. S. Li, S. L. Da, Y. Q. Feng and M. Liu, J. Chromatogr. A, 2004, 1040, 53-61.

27 H. Chen, X. J. Liu, C. Yang, J. Gao, C. W. Ye and X. J. Li, Chromatographia, 2009, 70, 883-890.

28 G. Delahousse, V. Peulon-Agasse, J. Debray, M. Vaccaro, G. Cravotto, I. Jabin and P. Cardinael, J. Chromatogr. A, 2013, 1318, 207-216.

29 J. H. Park, H. J. Lim, Y. K. Lee, J. K. Park, B. E. Kim, J. J. Ryoo and K. Lee, J. Sep. Sci., 1999, 22, 679-682.

30 J. Xing, J. S. Li, C. Y. Wu, Y. Y. Chen, X. R. Lu and H. M. Han, Anal. Lett., 1999, 32, 3071-3081.

31 P. Shahgaldian, M. A. Sciotti and U. Pieles, Langmuir, 2008, 24, 8522-8526.

32 H. Huang, D. M. Li, W. Z. Wang, Y. C. Chen, K. Khan, S. Song and Y. S. Zheng, Org. Biomol. Chem., 2012, 10, 729-735.

33 Y. H. Yang, M. L. Qi and J. L. Wang, J. Chromatogr. A, 2018, 1578, 67-75.

34 J. He, L. N. Yu, X. B. Huang and M. L. Qi, J. Chromatogr. A, 2018, 1578, 67-75.

35 J. L. Peng, T. Sun, L. Q. Wu, M. L. Qi and X. B. Huang, RSC Adv., 2017, 7, 45408-45415.

36 W. O. McReynolds, J. Chromatogr. Sci., 1970, 8, 685-691.

37 T. Sun, H. Chen, X. G. Qiao, L. F. Ma, S. Q. Hu and X. M. Liu, RSC Adv., 2018, 8, 34102-34109.

38 C. Ragonese, D. Sciarrone, P. Q. Tranchida, P. Dugo and L. Mondello, J. Chromatogr. A, 2012, 1255, 130-144.

39 C. F. Poole and S. K. Poole, J. Chromatogr. A, 2008, 1184, 254280.

40 B. Mayer-Helm and W. Rauter, Analyst, 2005, 130, 502-507. 41 J. L. Anderson and D. W. Armstrong, Anal. Chem., 2003, 75, 4851-4858.

42 K. Roeleveld, F. David and F. Lynen, J. Chromatogr. A, 2016, 145, 135-144. 